\title{
Depth separation fails to modulate the orientation-inhibition effect
}

\author{
SHELDON M. EBENHOLTZ \\ University of Wisconsin-Madison, Madison, Wisconsin
}

\begin{abstract}
When a rod-and-frame display has a circumscribing circle added to it, the usual orientation effect is greatly reduced or neutralized (Ebenholtz \& Utrie, 1982, 1983). Placing a depth interval between frame and circle, the frame beyond or in front of the circle, produced no significant decrement in the orientation-inhibition effect (OIE) relative to an apparent coplanar condition. It is proposed that the OIE and other phenomena that are insulated from effects of depth separation be regarded as instances of ambient system processing (Leibowitz \& Post, 1982).
\end{abstract}

The RFE, or rod-and-frame effect (Witkin \& Asch, 1948), represents a large-scale illusion of spatial orientation mediated by peripheral visual stimulation (Ebenholtz, 1977). As such, it shares important characteristics with other phenomena of induced self-movement, especially roll vection, which are best understood as examples of visual-vestibular interactions (Dichgans \& Brandt, 1978).

Several recent studies have shown that the static visualvestibular interaction prompted by a tilted framework can be modulated by the presence of circular contours in the retinal periphery (Ebenholtz \& Utrie, 1982, 1983; Streibel, Barnes, Julness, \& Ebenholtz, 1980). The circular contour neutralized the effects of the tilted frame to about $25 \%$ of initial values, but only when it circumscribed the frame; it was ineffective when inscribed within the frame. As such, it represents yet another case of the dominant role of peripheral stimulation in the control of spatial orientation (Leibowitz \& Post, 1982).

The mechanisms underlying this orientation-inhibition effect (OIE) remain to be investigated, one potentially significant variable being the relative depth interval between frame and circle. Although, when the frame projects more than about $7^{\circ}$ at the retina, the RFE itself is not influenced by the presence of a depth interval between rod and frame (Ebenholtz \& Glaser, 1982), many other phenomena, including a small-frame RFE (Ebenholtz \& Glaser, 1982; Gogel, 1978), induced movement (Gogel, 1978), apparent lightness (Gilchrist, 1980), visual masking (Lehmkuhle \& Fox, 1980) and the inhibitory interactions of an annulus on the apparent clarity and detectability of gap orientation in a Landolt C figure (Fox \& Patterson, 1981), are heavily influenced by depth separation. The present study, therefore, examined the role of depth separation, between a circular luminous contour and a tilted luminous frame (and rod) within it, in the orientation inhibition effect.

This research was supported in part by Grant BNS 82-01411 from the National Science Foundation. The conscientious aid of John Utrie, $\mathrm{J}_{\mathrm{r} . \text {, is gratefully acknowledged. }}$

The author's mailing address is: Department of Psychology, Charter at Johnson, University of Wisconsin, Madison, WI 53706.

\section{METHOD}

\section{Apparatus}

The rod and frame were made of electroluminescent panels, the square frame in Experiment 1 being $106.5 \mathrm{~cm}$ on a side and having a width of $2.3 \mathrm{~cm}$. The rod was $95.5 \times 2.3 \mathrm{~cm}$. Circumscribing the frame was a luminous circular contour that had an inner diameter of $160.8 \mathrm{~cm}$ and a width of $1.2 \mathrm{~cm}$. Observers were at $113 \mathrm{~cm}$ from the circle, while the frame was $47 \mathrm{~cm}$ beyond the circle. This corresponded to a binocular disparity of $.92^{\circ}$ of arc. In terms of retinal angle, the diameter, measured to the outer edge of the circle, projected $71.3^{\circ}$, while the frame diagonal produced an angle of $50.4^{\circ}$ at the retina.

In Experiment 2, the frame was $35.6 \mathrm{~cm}$ on a side and had a width of $.8 \mathrm{~cm}$; the rod was $29 \times .8 \mathrm{~cm}$. The same circle as previously described was again viewed from $113 \mathrm{~cm}$, as in Experiment 1, but the frame was placed at $53.5 \mathrm{~cm}$ from the observer. At this distance, the frame diagonal again produced a retinal angle of $50.4^{\circ}$, exactly as in Experiment 1 . The retinal disparity produced by the $59.5-\mathrm{cm}$ separation between frame and circle equaled $3.5 \mathrm{deg}$. Thus, except for a $3^{\circ}$ difference in the retinal projection of the rod, ${ }^{1}$ both frame and circle provided equal retinal angles in the two experiments.

\section{Procedure}

The RFE was measured in terms of the algebraic difference in judgments of the apparent vertical taken first without the frame and then in the presence of the tilted frame, the latter at a clockwise angle of $22.5^{\circ}$. Line settings were made from starting positions at $25^{\circ}$ on either side of vertical, with instructions to match the egocentric orientation defined as the chin-to-forehead, or 6-to-12o'clock, direction. In both experiments, subjects took part in two sessions at least $24 \mathrm{~h}$ apart. The first session was always under monocular viewing with the dominant eye. Binocular measures were taken only at the second session in order to avoid any possible memory effects of a prior depth experience. To establish eye dominance, the subjects pointed with the right index finger while each eye was successively covered to determine the coincidence of the images of the pointing finger and the target.

After the final rod setting of each session, the frame and circle were illuminated, the subject's attention was directed toward the center of the frame, and he or she was asked to provide an estimate, in feet and inches, of the depth separation between frame and circle.

\section{Subjects and Design}

Sixteen subjects took part in Experiment 1 and eight took part in Experiment 2; the genders were equally represented in each case. In each session, the RFE was measured both as described earlier 
Table 1

Depth Estimates (in Centimeters) of Circle-to-Frame Separations of $47 \mathrm{~cm}$ (Experiment 1) and $59.5 \mathrm{~cm}$ (Experiment 2)

\begin{tabular}{cccccc}
\hline & \multicolumn{2}{c}{ Binocular } & & \multicolumn{2}{c}{ Monocular } \\
\cline { 2 - 3 } \cline { 5 - 6 } & $\mathrm{M}$ & $\sigma_{\mathrm{M}}$ & & $\mathrm{M}$ & $\sigma_{\mathrm{M}}$ \\
\hline Experiment 1 & 43.33 & 6.94 & & 8.10 & 6.94 \\
Experiment 2 & 71.12 & 8.37 & & 3.65 & 3.95 \\
\hline
\end{tabular}

and with the addition of rod settings, also without the frame and then with it, in the presence of the surrounding circular contour. The order of circle and no-circle conditions was counterbalanced over subjects in both experiments. Thus, in each experiment, a within-subjects design was used to compare both circle/no-circle conditions within sessions and depth/no-depth between sessions.

\section{RESULTS}

\section{Apparent Depth Estimates}

The first question to be answered concerned the effectiveness of the monocular and binocular viewing conditions in producing differences in apparent depth separation between circle and frame. Depth estimates for all conditions and both experiments are shown in Table 1 . In neither experiment was the apparent-depth estimate under monocular viewing significantly different from zero, whereas under binocular viewing it was $[\mathrm{t}(15)=6.24$, $\mathrm{p}<.01$, in Experiment 1 and $\mathrm{t}(7)=8.5, \mathrm{p}<.01$ in Experiment 2. Furthermore, in Experiment 1, the obtained value of $43.33 \mathrm{~cm}$ did not depart significantly from the actual depth interval of $47.0 \mathrm{~cm}[\mathrm{t}(15)=0.53, \mathrm{p}>$ .05]. Likewise, in Experiment 2, the obtained mean of 71.12 did not depart significantly from the actual interval of $59.5 \mathrm{~cm}[t(7)=1.40, p>.05]$. Finally, the estimates made under binocular and monocular viewing did differ significantly from each other $[\mathrm{t}(15)=5.22, \mathrm{p}<$ .01 , in Experiment 1 and $t(7)=7.46, p<.01$, in Experiment 2]. There is, thus, no doubt that the depth interval was experienced under binocular viewing but was essentially absent under monocular conditions. It may also be noted that the quality of the depth experience was such that no subject reported, when questioned, that double images were present.

\section{Orientation Inhibition Effects}

Experiment 1. Table 2 shows the RFE for all subjects and also for the eight highest and eight lowest scorers. Under binocular conditions, the frame without circle produced significantly higher RFE scores than the framein-circle condition. This was the case for the total sample $[t(15)=4.66, p<.01]$, as well as for the highest $[\mathrm{t}(7)=5.13, \mathrm{p}<.01]$ and lowest $[\mathrm{t}(7)=2.69, \mathrm{p}<$ $.02]$ scorers. Thus, binocular viewing under a depth interval produced reliable and significant orientationinhibition effects. Monocular viewing produced a similar pattern of results. For the total sample, $t(15)=4.32$; the highest eight scorers yielded $\mathrm{t}(7)=7.15, \mathrm{p}<.01$, in each case. The lowest eight also showed a decrement in the RFE in the presence of the circular contour, but the difference with respect to the circle-absent condition was not significant $[\mathrm{t}(7)=1.46, \mathrm{p}>.05]$.

Since the orientation inhibition effect was in evidence under binocular and monocular viewing, the question to be answered was whether the extant differences in depth produced corresponding differences in the magnitude of the OIE. Accordingly, RFE scores under monocular and binocular conditions were compared in the frame alone and also in the frame-in-circle conditions, once with all 16 subjects and separately for the 8 highest and 8 lowest scoring subjects. In no case was the obtained difference significantly different from zero. Experiment 1 thus shows that, with the frame beyond the circle, apparent depth separation had no influence whatsoever on the OIE.

Experiment 2. With the frame in front of the circle, under binocular viewing, the RFE was significantly greater when the circumscribing circle was absent than when it was present $[\mathrm{t}(7)=4.91, \mathrm{p}<.01]$. The same pattern occurred under monocular viewing $[t(7)=3.46$, $\mathrm{p}<.01 \mathrm{~J}$. Thus, the OIE was evidenced under both the presence and the absence of depth. Further analysis also showed no significant differences in RFE between binocular and monocular conditions for either the frame-withoutcircle $[t(7)=1.54, p>.05]$ or the frame-in-circle conditions $[\mathrm{t}(7)=0.86, \mathrm{p}>.05]$.

Considering both experiments, it is clear that neither relative depth nor any particular direction of relative depth altered, in any way, the occurrence or magnitude of the OIE.

\section{DISCUSSION}

In the present studies, the circular contour neutralized the RFE to the extent of about $35 \%$ to $40 \%$ of initial level in Experiment 1 and from $16 \%$ to $21 \%$ in Experiment 2,

Table 2

RFE (in Degrees) Under Depth (Binocular) and Apparent Coplanar (Monocular) Viewing, With and Without a Surrounding Circular Contour

\begin{tabular}{|c|c|c|c|c|c|c|c|c|}
\hline & \multicolumn{4}{|c|}{ Binocular } & \multicolumn{4}{|c|}{ Monocular } \\
\hline & \multicolumn{2}{|c|}{$\begin{array}{c}\text { Frame Without } \\
\text { Circle }\end{array}$} & \multicolumn{2}{|c|}{$\begin{array}{l}\text { Frame in } \\
\text { Circle }\end{array}$} & \multicolumn{2}{|c|}{$\begin{array}{c}\text { Frame Without } \\
\text { Circle }\end{array}$} & \multicolumn{2}{|c|}{$\begin{array}{c}\text { Frame in } \\
\text { Circle }\end{array}$} \\
\hline & $\mathbf{M}$ & $\sigma_{\mathbf{M}}$ & $\mathbf{M}$ & $\sigma_{\mathrm{M}}$ & $\mathbf{M}$ & $\sigma_{\mathbf{M}}$ & $\mathbf{M}$ & $\sigma_{\mathrm{M}}$ \\
\hline Total Sample $(n=16)$ & $3.75^{*}$ & .73 & $1.53 *$ & .40 & $4.48^{*}$ & .84 & $1.61^{*}$ & .39 \\
\hline Highest 8 Scores & $6.00^{*}$ & .77 & $2.63 *$ & .43 & $7.31^{*}$ & .62 & $2.66^{*}$ & .50 \\
\hline Lowest 8 Scores & $1.50 *$ & .48 & 0.44 & .40 & $1.66^{* *}$ & .59 & $0.56 * *$ & .29 \\
\hline Experiment $2(n=8)$ & $4.99 *$ & .89 & $0.82 *$ & .23 & $5.76^{*}$ & .98 & $1.21^{*}$ & .40 \\
\hline
\end{tabular}

*Significantly different from zero at $p<.01 . \quad * *$ Significantly different from zero at $p<.05$. 
ranging over monocular and binocular conditions. Even though considerable neutralization occurred, however, a readily appreciated depth interval between frame and circle failed to modulate the OIE. In light of the many contrasting instances of depth separation effects (Fox \& Patterson, 1981; Gilchrist, 1980; Gogel, 1978), there is a need for a unifying principle. The concept of two visual systems (Held, 1968; Ingle, 1967; Schneider, 1967; Trevarthen, 1968) provides such a function.

With this approach, one can distinguish two modes of processing (Leibowitz \& Post, 1982) that are associated with an ambient and a focal system, respectively. Accordingly, instances of depth-separation effects based upon binocular disparity may be regarded as manifestations of focal-system processing subserving such functions as may aid cognitive discrimination among objects, for example, size and form perception, recognition, and identification. On the other hand, phenomena that are insulated from the effects of depth separation as well as from the influence of other focal-system qualities, such as apparent size and form (Ebenholtz, 1977; Streibel et al., 1980), can best be understood as instances of ambient-system processing. These latter phenomena, which are mediated by peripheral retinal processing, tend to function automatically, that is, with minimal cognitive control, and to contribute to the control of spatial orientation. Both the RFE itself and the OIE thus qualify as clear cases of ambient-system processing.

\section{REFERENCES}

Dichgans, J., \& BrandT, TH. (1978). Visual-vestibular interactions: Effects on self-motion perception and postural control. In R. Held, H. Leibowitz, \& H. L. Teuber (Eds.), Handbook of sensory physiology: Vol. VIII. Perception. New York: Springer.

EbENHoltz, S. M. (1977). Determinants of the rod and frame effect: The role of retinal size. Perception \& Psychophysics, 22, 531-538.

EBENHOLTZ, S. M. (1985). Absence of relational determination in the rod-and-frame effect. Perception \& Psychophysics, 37, 303-306.

Ebenholtz, S. M., \& Glaser, G. W. (1982). Absence of depth process- ing in large-frame rod-and-frame effect. Perception \& Psychophysics, 32, 134-140.

Ebenholtz, S. M., \& UTRIE, J. W., JR. (1982). Inhibition of the rodand-frame effect by circular contours. Perception \& Psychophysics, 32, 199-200.

Ebenholtz, S. M., \& UTRIE, J. W., JR. (1983). Peripheral circular contours inhibit the visual orientation control system. Aviation, Space, and Environmental Medicine, 54, 343-346.

Fox, R., \& Patterson, R. (1981). Depth separation and lateral interference. Perception \& Psychophysics, 30, 513-520.

GiLCHRIST, A. (1980). When does perceived lightness depend on perceived spatial arrangement. Perception \& Psychophysics, 28, 527-538.

GOGEL, W. C. (1978). The adjacency principle in visual perception. Scientific American, 238, 126-139.

HeLD, R. (1968). Dissociation of visual functions by deprivation and rearrangement. Psychologische Forschung, 31, 338-348.

INGLE, D. (1967). Two visual mechanisms underlying the behavior of fish. Psychologische Forschung, 31, 44-51.

LEHMKUHLE, S., \& Fox, R. (1980). Effect of depth separation on metacontrast masking. Joumal of Experimental Psychology: Human Perception and Performance, 6, 605-621.

Leibowitz, H. W., Post, R. B. (1982). The two modes of processing concept and some implications. In J. J. Beck (Ed.), Organization and representation in perception. New York: Erlbaum.

SCHNEIDER, G. E. (1967). Contrasting visuomotor functions of tectum and cortex in the golden hamster. Psychologische Forschung, 31, 52-62.

Streibel, M. J., Barnes, R. D., Julness, G. D., \& Ebenholtz, S. M. (1980). Determinants of the rod-and-frame effect: Role of organization and subjective contour. Perception \& Psychophysics, 27, 136-140.

Trevarthen, C. (1968). Two mechanisms of vision in primates. Psychologische Forschung, 31, 229-337.

WITKIN, H. A., \& Asch, S. E. (1948). Studies in space orientation: IV. Further experiments on perception of the upright with displaced visual fields. Journal of Experimental Psychology, 38, 762-782.

\section{NOTES}

1. Evidence indicates no significant effects on the RFE of changes in rod length even for a reduction in excess of $1 / 5$ the length of the long rod in Experiment 1 (Ebenholtz, 1985).

(Manuscript received October 23, 1984; revision accepted for publication April 11, 1985.) 